\title{
Etefom e épocas de poda no crescimento de videira rústica ${ }^{1}$
}

\author{
Camila Meira de Abreu², Luiz Fernandes Cardoso Campos ${ }^{3}$, Diego Palmiro Ramirez Ascheri ${ }^{2}$, \\ Alexsander Seleguini ${ }^{4}$
}

$10.1590 / 0034-737 X 201663060012$

\begin{abstract}
RESUMO
Em regiões tropicais, a videira necessita de cuidados diferentes daqueles exigidos nas regiões de clima temperado por causa do seu crescimento contínuo. Técnicas como a aplicação de reguladores de crescimento e a alternância de podas tornam-se essenciais para uma exploração satisfatória da viticultura, proporcionando duas ou mais colheitas por ano. Objetivou-se avaliar o efeito de diferentes épocas de poda, aliadas a doses de Etefom, no crescimento da videira 'Isabel' em dois ciclos de produção. Dois experimentos foram realizados utilizando delineamento em blocos casualizados, compostos de 16 tratamentos, dispostos no esquema fatorial 4 x 4, com quatro repetições. Avaliaram-se quatro épocas de poda em duas safras: inverno (08/março, 22/março, 05/abril e 19/abril de 2013) e verão (25/agosto, 8/setembro, 22/ setembro e 06/outubro de 2013). O segundo fator de variação consistiu das quatro doses de Etefom (0, 720, 1.440, 2.160 $\mathrm{mg} \mathrm{L}^{-1}$ ). As variáveis avaliadas foram a duração do ciclo produtivo da videira, o diâmetro da base dos ramos, o comprimento de ramos, a percentagem de brotação e o número de brotos por gema. $\mathrm{O}$ fator época de poda foi avaliado pelo teste de Tukey, a 5\% de probabilidade, e o fator concentrações de Etefom, por análise de regressão. Na safra de inverno, a videira Isabel apresentou os menores ciclos, enquanto na safra de verão os ciclos foram mais longos. Na safra de verão, poda realizada no início de outubro proporcionou maior comprimento de ramos, enquanto na safra de inverno isso ocorre nas podas realizadas em abril. As concentrações de Etefom influenciaram o crescimento da videira apenas na safra de verão, com efeito linear positivo para comprimento dos ramos e efeito quadrático, aumentando a brotação até a dose de $1440 \mathrm{mg} \mathrm{L}^{-1}$.
\end{abstract}

Palavras-chave: Vitis labrusca L.; cultivar Isabel; exigência térmica; regulador de crescimento.

\section{ABSTRACT}

\section{Ethephon and pruning seasons on the growth of rustic vine}

In tropical regions, vine needs different care than those required in temperate regions because of its continuous growth. Techniques such as the application of growth regulators and the alternation of pruning become essential for a satisfactory exploitation of viticulture, providing two or more crops per year. The objective of this study was to evaluate the effect of different pruning times, coupled with Ethephon doses, on the growth of 'Isabel' grapevine in two production cycles. Two experiments were carried out using a randomized block design, composed of 16 treatments, arranged in a $4 \times 4$ factorial scheme, with four replications. Four pruning seasons were evaluated in two crops: Winter (March 08, March 22, April 05, and April 19, 2013) and Summer (August 25, September 08, September 22, and October 06, 2013). The second variation factor consisted of four doses of Ethephon $\left(0,720,1440,2160, \mathrm{mg} \mathrm{L}^{-1}\right)$. The evaluated variables were the duration of the productive cycle of the vine, the diameter of the base of the branches, the length of

\footnotetext{
Submetido em 05/11/2014 e aprovado em 19/07/2016.

'Este trabalho é parte da dissertação de mestrado da primeira autora. Bolsa concedida pela coordenação de aperfeiçoamento de pessoal de nível superior (CAPES).

${ }^{2}$ Universidade Estadual Goiás, Departamento de Engenharia Agrícola, Anápolis, Goiás, Brasil. camilaabreuagro@hotmail.com; ascheridpr@gmail.com

${ }^{3}$ Universidade Federal de Goiás, Programa de Pós-graduação em Agronomia, Goiânia, Goiás, Brasil. luizfernandescampos@hotmail.com

${ }^{4}$ Universidade Federal de Goiás, Escola de Agronomia, Departamento de Horticultura, Goiânia, Goiás, Brasil. aseleguini@gmail.com

*Autora para correspondência: camilaabreuagro@hotmail.com
} 
branches, the sprouting percentage, and the number of shoots per bud. The pruning seasons factor was evaluated by the Tukey test, at $5 \%$ probability and the factor Ethephon concentrations by regression analysis. In the Winter crop, the Isabel vine presented the smallest cycles, while in the Summer crop the cycles were longer. In the Summer harvest, pruning performed in early October provided a longer length of branches, while in the Winter season this occurs in the pruning performed in April. Concentrations of Ethephon influenced vine growth only in the Summer crop, with positive linear effect for branch length and quadratic effect, increasing sprouting up to the dose of $1440 \mathrm{mg} \mathrm{L}^{-1}$.

Key words: Vitis labrusca L.; Isabel cultivar; thermal demand; growth regulator.

\section{INTRODUÇÃO}

Existe no Estado de Goiás uma demanda, principalmente dos pequenos produtores, por pesquisas e tecnologias que possam alavancar a atividade frutícola. Nesse contexto, a viticultura surge com enorme potencial econômico para o Estado de Goiás (Faria et al., 2013). Vários municípios já praticam a viticultura, segundo dados do ano de 2013, obtidos junto à Agência Goiana de Defesa Agropecuária (Agrodefesa). A área plantada no Estado é de 211,45 ha distribuídos em 28 municípios. Os municípios com maiores áreas cultivadas são Paraúna (21,75\%), Santa Helena de Goiás (21\%), Cocalzinho (16,1\%), Itaberaí (4,92\%) e Hidrolândia (4,21\%), correspondendo a 67,98\% da área plantada com uvas no Estado de Goiás. Vinte e quatro variedades são cultivadas sendo as mais plantadas a Isabel, Niágara (rosada e branca), a Syrah e a BRS Cora, correspondendo, respectivamente, a 67,6 ha; 40,03 ha; 16,33 ha e 13,1 ha. Dentre as variedades plantadas, há grande diversidade de uvas para mesa, vinhos e suco, com predominância de uvas rústicas (Semensato et al., 2015).

A viticultura tropical é típica de regiões em que as temperaturas mínimas não são suficientemente baixas para induzir a videira à dormência. Seu crescimento é contínuo, havendo necessidade de técnicas apropriadas para obtenção de duas ou mais colheitas por ano. A colheita pode ser programada para qualquer época do ano (Camargo et al., 2011). No entanto, há necessidade de realização de podas ou do uso de reguladores de crescimento. Dentre estas técnicas podem-se citar o uso de diferentes tipos de poda (leve ou drástica), além do escalonamento dessa poda, e o de reguladores de crescimento.

A data de poda é uma referência para o início do ciclo fenológico da videira, que é influenciado pelas condições de climáticas da região (Neis et al., 2010). De acordo com Silva et al. (2006), o atraso ou a antecipação da maturação dos cachos, promovidos pelas diferentes épocas de podas, podem ser interessantes para o viticultor, uma vez que permite o escalonamento da colheita e a consequente comercialização dos frutos em períodos de preços mais atrativos. Cada espécie ou cultivar do gênero Vitis pode apresentar diferentes ciclos fenológicos, a depender de fatores genéticos e ambientais como clima e solo e, ainda, dos mais diversos tratos culturais (Anzanello et al., 2012).

Em regiões de clima tropical, ocorre o crescimento vegetativo ininterrupto e a morte de gemas basais nas videiras, tornando-se indispensável o uso de duas podas anuais, para adequada manutenção da estrutura das plantas e controle da produtividade. Como as plantas não entram em dormência, a poda é realizada com plantas em plena vegetação, havendo a necessidade de desfolha manual ou induzida com a aplicação de reguladores de crescimento (Camargo, 2004).

O Etefom tem sido usado como um produto eficaz para aumento de brotação de gemas de videiras, em condições tropicais (Schenato et al., 2007). Aplicações sucessivas em videiras provocam o aumento da fertilidade e estimulam a brotação das gemas de ciclos anteriores, aumentando a produtividade da cultura (Fracaro et al., 2004a; Fracaro at al., 2004b). Além disso, a aplicação foliar de Etefom em videiras tem-se mostrado eficaz para o aumento do crescimento e do diâmetro dos ramos, aumento do comprimento, largura e massa dos cachos (Fracaro \& Pereira, 2004). Esses resultados podem estar associados à maior mobilização de nutrientes e carboidratos das folhas para órgãos, como ramos, caule e raízes, os quais são redistribuídos para as partes em crescimento no ciclo vegetativo seguinte, fenômeno comum na videira (Conradie, 1991; Zapata et al., 2004; Brunetto et al., 2005).

Trabalhos visando à definição de épocas de poda e de comportamento fenológico são necessários para melhor planejamento da produção, além da interação com o uso de reguladores de crescimento. Assim, objetivou-se, com este experimento, avaliar, o efeito de diferentes épocas de poda em dois ciclos de produção, aliadas a doses de Etefom, no crescimento e no ciclo da videira 'Isabel'.

\section{MATERIAL E MÉTODOS}

O experimento foi realizado no município de Itapuranga, GO, na Fazenda Capoeira Grande, com coordenadas geográficas $15^{\circ} 34^{\prime} 32^{\prime \prime} \mathrm{S}, 50^{\circ} 00^{\prime} 31^{\prime \prime} \mathrm{O}$ e altitude média de 635 m. De acordo com a classificação de Koppen, o clima pre- 
dominante na região é do tipo Aw (tropical com estação seca de inverno). O solo da área experimental foi classificado como Latossolo Vermelho distrófico (Embrapa, 2013), cujas características químicas e físicas antes da instalação do experimento, na camada de $0 \mathrm{~cm}$ a $20 \mathrm{~cm}$ de profundidade foram: $\mathrm{pH}$ em $\mathrm{CaCl}_{2}=6,2 ;$ Matéria Orgânica $=38 \mathrm{~g}$ $\mathrm{dm}^{-3} ; \mathrm{PMehlich}=3,8 \mathrm{mg} \mathrm{dm}^{-3} ; \mathrm{Al}^{3+}=0,0 \mathrm{cmol}_{\mathrm{c}} \mathrm{dm}^{-3} ; \mathrm{H}+\mathrm{Al}$ $=1,7 \mathrm{cmol} \mathrm{dm}^{-3} ; \mathrm{K}^{+}=0,27 \mathrm{cmol}_{\mathrm{c}} \mathrm{dm}^{-3} ; \mathrm{Ca}^{2+}=5,6 \mathrm{cmol}_{\mathrm{c}} \mathrm{dm}^{-}$ 3; $\mathrm{Mg}^{2+}=2,6 \mathrm{cmol}_{\mathrm{c}} \mathrm{dm}^{-3} ; \mathrm{S}=8,47 \mathrm{cmol}_{\mathrm{c}} \mathrm{dm}^{-3} ; \mathrm{CTC}=9,2$ $\mathrm{cmol}_{\mathrm{c}} \mathrm{dm}^{-3} ; \mathrm{V}=81,5 \%$; argila $=440 \mathrm{~g} \mathrm{~kg}^{-1} ;$ silte $=180 \mathrm{~g} \mathrm{~kg}^{-}$ ${ }^{1}$ e areia $=380 \mathrm{~g} \mathrm{~kg}^{-1}$.

A área experimental foi instalada em parreiral com dois anos de idade, após a enxertia da videira 'Isabel' em porta-enxerto IAC 572 'Jales', tendo sido irrigada por microaspersão e conduzida em sistema de latada, no espaçamento de $2,5 \mathrm{~m}$ x 2,5 m.

Dois experimentos foram conduzidos, aqui denominados de safra de inverno e safra de verão, na mesma área e plantas. $\mathrm{O}$ experimento da safra de inverno foi iniciado em fevereiro e finalizado em agosto de 2013 e o de safra de verão foi de agosto de 2013 a fevereiro de 2014. Na safra de inverno, as videiras foram submetidas à poda longa, deixando-se cinco gemas por vara. Na safra de verão, as videiras foram submetidas à poda curta deixando-se duas gemas por vara.

Em cada safra foram implantados 16 tratamentos utilizando-se delineamento em blocos casualizados, no esquema fatorial $4 \times 4$, com quatro repetições. Cada parcela continha uma planta de videira, num total de 64 plantas $\left(400 \mathrm{~m}^{2}\right)$. O primeiro fator foi composto pelas épocas de poda nas safras de inverno (08/março, 22/março, 05/abril e 19/abril de 2013) e de verão (25/agosto, 8/setembro, 22/ setembro e 06/outubro de 2013). O segundo fator consistiu em quatro concentrações de Etefom $(0,720,1.440,2.160$ $\left.\mathrm{mg} \mathrm{L}^{-1}\right)$. As concentrações estudadas foram: metade da dose recomendada $\left(720 \mathrm{mg} \mathrm{L}^{-1}\right)$, a dose recomendada (1.440 $\left.\mathrm{mg} \mathrm{L}^{-1}\right)$ e duas vezes a dose recomendada $\left(2.160 \mathrm{mg} \mathrm{L}^{-1}\right)$ (Fracaro et al., 2004a). O produto foi diluído em água e aplicado sobre as plantas enfolhadas, com pulverizador costal até o ponto de escorrimento, 20 dias antes de cada poda.

Após cada poda, realizou-se a superação da dormência das gemas com Cianamida hidrogenada, por meio de pincelamento com rolo de espuma. Os tratos culturais utilizados pelo produtor na safra de inverno foram: adubação com $35 \mathrm{~g}$ planta de $\mathrm{P}_{2} \mathrm{O}_{5}$ (superfosfato simples), dez dias antes da poda; 20 g planta de N (ureia), aos 15 e 45 dias após a poda; 25 g planta de FTE BR12, aos 15 dias após a poda; e $15 \mathrm{~g}$ planta de $\mathrm{K}_{2} \mathrm{O}$, (cloreto de potássio), aos 80 dias após a poda. No controle fitossanitário foram realizadas pulverizações com Metiram + Piraclostrobina e Metalaxil-M + Mancozebe. Os tratos culturais na safra de verão foram: adubação com 8, 60 e 20 g planta $^{-1}$ de N, $\mathrm{P}_{2} \mathrm{O}_{5}$ e $\mathrm{K}_{2} \mathrm{O}$, respectivamente, com o formulado 4-30-10, dez dias antes da poda; $20 \mathrm{~g} \mathrm{planta}^{-1}$ de $\mathrm{N}$ (uréia), aos 15 e 45 dias, após a poda; e $15 \mathrm{~g}$ planta $^{-1}$ de $\mathrm{K}_{2} \mathrm{O}$ (cloreto de potássio), aos 80 dias após a poda. No controle fitossanitário foram feitas pulverizações com Metalaxil-M + Mancozebe, Tiofanato-Metílico + Clorotalonil e Azoxistrobina + Difenoconazol.

Os dados climáticos da região foram obtidos da estação meteorológica da Cidade de Goiás, GO, durante o ano de 2013 e início de 2014 (Tabela 1). O ciclo produtivo da videira foi registrado, contando-se o número de dias desde a poda até a colheita. Para a caracterização das exigências térmicas do cultivar, foi utilizado o somatório de graus-dia (GD), desde a poda até a colheita, calculado segundo a metodologia proposta por Villa Nova et al. (1972), adotando-se a temperatura-base de $10^{\circ} \mathrm{C}$ (Santos et al., 2007):

$G D=(T m-T b)+\frac{T M-T m}{2}$, para $T m>T b ;$

$G D=\frac{(T m-T b)+2}{2+(T M-T m)^{2}}$, para $\mathrm{Tm}<\mathrm{Tb}$; e $G D=0$, para

$\mathrm{Tb}>\mathrm{TM}$, em que TM é a temperatura máxima diária $\left({ }^{\circ} \mathrm{C}\right)$; Tm é a temperatura mínima diária $\left({ }^{\circ} \mathrm{C}\right)$; e Tb é a temperatura base $\left({ }^{\circ} \mathrm{C}\right)$.

As plantas foram avaliadas quanto a seu crescimento, no período de pleno florescimento, pelas variáveis diâmetro da base dos ramos, comprimento de ramos, porcentagem de brotação e número de brotos por gema. O diâmetro da base dos ramos foi mensurado com paquímetro; o comprimento de ramos com trena; a percentagem de brotação foi calculada pela relação entre o número de gemas brotadas; e o número total de gemas deixadas no momento da poda.

Os dados obtidos foram submetidos à análise de variância (ANOVA), com a significância dos efeitos dos tratamentos determinada pelo teste F. As médias das épocas de poda foram comparadas pelo teste de Tukey, a 5\% de probabilidade, e o fator concentrações de Etefom foi avaliado por meio de análise de regressão.

\section{RESULTADOS E DISCUSSÃO}

O maior ciclo de produção da videira Isabel ocorreu na safra de verão, quando a poda foi realizada em 23/09/2013, com 150 dias (1.801 GD), e o menor ciclo ocorreu na safra de inverno, quando a poda foi realizada em 10/07/2013, de 124 dias (1483,9 GD) (Tabela 2). Os ciclos longos na safra de verão podem ser explicados pela ocorrência de chuvas nos meses de outubro a fevereiro (Tabela 1), causando atraso na maturação da uva, além do acúmulo de grausdia nesse período ter sido menor (Tabela 2). De acordo com Jacskon \& Cherry (1988), altos índices de precipita- 
ção pluviométrica podem afetar a maturação das bagas, causando atraso nesta fase, o que impede que as bagas atinjam a maturação completa.

Para a safra de inverno, foi calculada uma soma térmica média de $1.623 \mathrm{GD}$, da poda à colheita, enquanto para safra de verão foi observada soma térmica média de 1.746,9 GD. Ribeiro et al. (2009) obtiveram resultados semelhantes para uva 'Niágara Rosada', cultivada no município de Janaúba, norte de Minas Gerais, evidenciando maior soma térmica no período compreendido entre a poda e a colheita, em plantas podadas no verão, do que em plantas podadas no inverno. Os autores observaram soma térmica de 1.766 GD para a poda de verão e 1.838 GD para a poda de inverno. Diferentemente, Scarpare et al. (2012) observaram maior necessidade térmica para videiras de 'Niágara Rosada' podadas no inverno do que para as que recebe- ram poda de produção de verão, no município de Piracicaba, SP. Segundo Pedro Júnior \& Sentelhas (2003), a duração do ciclo das videiras pode variar entre regiões por causa das diferentes condições edafoclimáticas em que se localizam. Em locais com temperaturas elevadas, o crescimento vegetativo tende a ser maior e, o ciclo, ser mais curto do que os das regiões de clima mais ameno.

Para o cultivar 'Isabel', Regina et al. (2003) verificaram ciclo de 177 dias, no sul de Minas Gerais. Gomes et al. (2007), no Vale do São Francisco, observaram que a videira 'Isabel', enxertada sobre o IAC 572 'Jales', apresentou ciclo médio de 115 dias. Roberto et al. (2004) relatam ciclo de 127 dias, da poda à colheita, em Maringá, PR, enquanto Maia et al. (2002) verificaram que a videira 'Isabel', cultivada em Campina Verde, MG, no sistema de latada, apresenta ciclo de 140 dias. De acordo com Sato et al. (2008), a videira

Tabela 1: Precipitação pluviométrica, temperaturas máxima, mínima e média mensais, no período do experimento, dados obtidos em estação de aquisição automática de dados

\begin{tabular}{lcccc}
\hline \multirow{2}{*}{ Mês/ano } & \multicolumn{3}{c}{ Temperatura $\left({ }^{\circ} \mathbf{C}\right)$} & Precipitação $(\mathbf{m m})$ \\
\cline { 2 - 4 } & Mínima & Máxima & Média & 376,3 \\
jan/13 & 21,6 & 31,6 & 26,6 & 117,9 \\
fev/13 & 21,5 & 34,5 & 28,0 & 131,0 \\
mar/13 & 21,9 & 34,2 & 28,1 & 99,4 \\
abr/13 & 21,2 & 33,4 & 27,3 & 29,1 \\
mai/13 & 19,4 & 34,4 & 26,9 & 8,3 \\
jun/13 & 19,4 & 33,6 & 26,5 & 0 \\
jul/13 & 18,1 & 33,9 & 26,0 & 0 \\
ago/13 & 19,4 & 35,8 & 27,6 & 26,9 \\
set/13 & 22,3 & 36,7 & 29,5 & 144,9 \\
out/13 & 22,3 & 35,5 & 28,9 & 232,0 \\
nov/13 & 33,2 & 27,1 & 315,5 \\
dez/13 & 21,0 & 32,8 & 27,2 & 223,6 \\
jan/14 & 21,5 & 34,0 & 27,3 & 232,6 \\
fev/14 & 20,6 & 32,9 & 26,9 & \\
\hline
\end{tabular}

Fonte: INMET/Estação Meteorológica da Cidade de Goiás, 2014.

Tabela 2: Duração do ciclo produtivo e soma térmica, em graus-dia, calculada com temperatura base de $10^{\circ} \mathrm{C}$, para a videira Isabel, nas safras de inverno e de verão, em quatro épocas de poda

\begin{tabular}{|c|c|c|c|}
\hline Data da poda & Data da colheita & Ciclo (dias) & Graus-dia \\
\hline \multicolumn{4}{|c|}{ Inverno } \\
\hline $1^{\text {a }} 08 / 03 / 2013$ & $10 / 07 / 2013$ & 124 & 1483,9 \\
\hline $2^{a} 22 / 03 / 2013$ & 06/08/2013 & 137 & 1642,6 \\
\hline $3^{a} 05 / 04 / 2013$ & $20 / 08 / 2013$ & 137 & 1661,0 \\
\hline $4^{a} \quad 19 / 04 / 2013$ & $28 / 08 / 2013$ & 131 & 1603,3 \\
\hline & & 134 & 1623,0 \\
\hline \multicolumn{4}{|c|}{ Verão } \\
\hline $1^{\text {a }} 26 / 08 / 2013$ & $10 / 01 / 2014$ & 137 & 1689,4 \\
\hline $2^{a} 09 / 09 / 2013$ & $04 / 02 / 2014$ & 148 & 1802,8 \\
\hline $3^{a} 23 / 09 / 2013$ & $20 / 02 / 2014$ & 150 & 1801,0 \\
\hline $4^{a} 07 / 10 / 2013$ & $27 / 02 / 2014$ & 143 & 1692,9 \\
\hline \multicolumn{2}{|c|}{ Média } & 145 & 1746,9 \\
\hline
\end{tabular}


'Isabel' sobre o porta-enxerto '420-A' apresentou ciclo total mais longo (167 dias) do que sobre os porta-enxertos 'IAC 766 Campinas' e 'IAC 572 Jales', de 148 e 142 dias, respectivamente, no norte do Paraná. Silva et al. (2008) verificaram que a variedade 'Isabel' foi considerada mais tardia do que a 'Niágara Rosada' e a 'Kyoho', com um ciclo médio, da poda à colheita, de 124 dias, para dois anos de cultivo, no norte Fluminense.

O conhecimento do ciclo da cultura auxilia o produtor no planejamento da produção, podendo sua colheita ser programada para as épocas de menor oferta no mercado, além de facilitar no controle de doenças fúngicas, evitando os períodos de maior frequência de precipitação.

Com relação às épocas de poda, na safra de inverno, verificou-se efeito significativo sobre o comprimento de ramos, a percentagem de gemas brotadas e o número de brotos por gema (Tabela 3). O comprimento de ramos foi maior na terceira e quarta épocas de podas, realizadas no mês de abril de 2013. Scarpare Filho \& Watanabe (2004) obtiveram, no município de Atibaia, SP, tamanho de ramos, do cultivar 'Niágara Rosada', de 43,7 cm na poda de inverno. Segundo Fracaro et al. (2004a), o maior comprimento de ramos pode ser atribuído a temperaturas mais elevadas, ocorridas no período de brotação. Entretanto, neste experimento, não foram observadas temperaturas discrepantes entre as diferentes épocas de poda (Tabela 1).

Também na safra de inverno, a maior percentagem de gemas brotadas foi verificada na terceira época de poda, não diferindo, no entanto, do observado na primeira época (Tabela 3). A menor taxa de brotação foi verificada na quarta época de poda, que diferiu apenas da segunda época. Segundo Leão \& Silva (2003), na região do Vale do
São Francisco, as variedades de uva tem seu comportamento influenciado pelas épocas de poda, sendo que, para a maioria das variedades, as podas realizadas em abril e julho proporcionam maiores quantidades de brotação e fertilidade de gemas.

O maior número de brotos por gema, na safra de inverno, foi observado na segunda época de poda (Tabela 3), mas não é desejável para o produtor, pois se torna necessário tempo maior para realização da desbrota.

Na safra de verão, o comprimento de ramos foi significativamente maior na quarta época de poda (07/10/2013), mesmo resultado verificado para o diâmetro de ramos, sem diferir, porém, do observado na primeira e terceira época de poda (Tabela 4). Diferentemente, Monaco Neto \& Scarpare Filho (2012) observaram, para o comprimento de ramos do cultivar Niágara Rosada, na poda de verão, o tamanho médio de $27,86 \mathrm{~cm}$.

A percentagem de gemas brotadas apresentou resultado de $100 \%$ de brotação em todas as épocas de poda na safra de verão (Tabela 4). Quanto ao número de brotos por gema, não houve influência das datas de poda. Nas podas da safra de verão, foram deixadas duas gemas por vara (poda curta), o que pode ter contribuído para o resultado de melhor brotação, em comparação com o observado na safra de inverno.

Não foi verificada interação entre os fatores épocas de poda $\mathrm{x}$ dose de Etefom, nas duas safras. Com relação às doses de Etefom, na safra de inverno não se verificou influência significativa para nenhuma das variáveis (Tabela 3). Já para a safra de verão, foram observadas influências significativas para o comprimento de ramos e número de brotos por gema (Tabela 4). Observou-se que os efeitos das doses de Etefom apresentaram comportamen-

Tabela 3: Componentes morfológicos da videira Isabel na safra de inverno, em diferentes épocas de poda submetidas a doses de Etefom (mg L-1)

\begin{tabular}{|c|c|c|c|c|}
\hline Tratamentos & $\begin{array}{l}\text { Comprimento de ramos } \\
\mathrm{cm}\end{array}$ & $\begin{array}{l}\text { Diâmetro de ramos } \\
\text { mm }\end{array}$ & $\begin{array}{c}\text { Gemas brotadas } \\
\%\end{array}$ & $\begin{array}{c}\text { Brotos por gema } \\
\text { Brotos }^{-1}\end{array}$ \\
\hline \multicolumn{5}{|l|}{ Poda (P) } \\
\hline $1^{\mathrm{a}}(08-03-13)$ & $48,98 \mathrm{~b}$ & $5,30 \mathrm{a}$ & $46,25 \mathrm{ab}$ & $1,25 \mathrm{~b}$ \\
\hline $2^{\mathrm{a}}(22-03-13)$ & $50,10 \mathrm{~b}$ & $5,35 \mathrm{a}$ & $40,62 \mathrm{bc}$ & $1,81 \mathrm{a}$ \\
\hline $3^{\mathrm{a}}(05-04-13)$ & $62,56 \mathrm{a}$ & $5,44 \mathrm{a}$ & $59,50 \mathrm{a}$ & $1,11 \mathrm{~b}$ \\
\hline $4^{\mathrm{a}}(19-04-13)$ & $62,73 \mathrm{a}$ & $5,52 \mathrm{a}$ & $28,50 \mathrm{c}$ & $1,10 \mathrm{~b}$ \\
\hline Teste F & $8,05^{* *}$ & $0,27^{\mathrm{ns}}$ & $12,040^{* *}$ & $21,209^{* *}$ \\
\hline \multicolumn{5}{|l|}{ Etefom (E) } \\
\hline 0 & 50,47 & 5,13 & 42,88 & 1,13 \\
\hline 720 & 56,39 & 5,33 & 43,00 & 1,13 \\
\hline 1440 & 60,14 & 5,72 & 45,88 & 1,14 \\
\hline 2160 & 57,39 & 5,44 & 43,13 & 1,13 \\
\hline Teste F & $2,324^{\mathrm{ns}}$ & $1,661^{\mathrm{ns}}$ & $0,151^{\mathrm{ns}}$ & $1,042^{\mathrm{ns}}$ \\
\hline Teste $\mathrm{F}(\mathrm{P} \times \mathrm{E})$ & $1,266^{\mathrm{ns}}$ & $1,359^{\mathrm{ns}}$ & $0,453^{\text {ns }}$ & $0,500^{\mathrm{ns}}$ \\
\hline$\overline{\mathrm{CV}}(\%)$ & 19,05 & 14,12 & 33,93 & 23,12 \\
\hline
\end{tabular}

Médias seguidas por letra diferente, diferem entre si a $5 \%$ pelo teste de Tukey. ${ }^{*}$ significativo $(\mathrm{p}<0,05) ; * *$ significativo $(\mathrm{p}<0,01)$; ns não significativo. 
to linear positivo para o comprimento de ramos e efeito quadrático para número de brotos por gema. Resultados semelhantes foram obtidos por Fracaro \& Pereira (2004), em uva 'Niágara Rosada', em que, segundo os autores, a maior dose (2.160 $\left.\mathrm{mg} \mathrm{L}^{-1}\right)$ de Etefom proporcionou, na terceira semana, melhor desenvolvimento dos ramos.

Segundo Pinã \& Bautista (2006), o vigor e o desenvolvimento dos ramos das plantas é influenciado por fatores externos, como temperatura, água, elementos minerais e fotoperíodo, e por condições internas, como o balanço hormonal e a nutrição mineral.
Portanto, o uso de Etefom para a desfolha da videira pode trazer alguns benefícios, como maior rendimento da operação de poda, como relatado por Fracaro et al. (2004a). Entretanto o seu efeito na brotação não foi evidente e, por outro lado, o crescimento dos ramos foi afetado. Ramos demasiadamente longos são indesejáveis na viticultura, pelo efeito de dreno dos fotoassimilados para seu crescimento, em detrimento do desenvolvimento de inflorescências, o que acarreta baixa produtividade (Albuquerque et al., 2000).

Tabela 4: Componentes morfológicos da videira Isabel na safra de verão, em diferentes épocas de poda submetidas a doses de Etefom $\left(\mathrm{mg} \mathrm{L}^{-1}\right)$

\begin{tabular}{|c|c|c|c|c|}
\hline Tratamentos & $\begin{array}{l}\text { Comprimento de ramos } \\
\text { mm }\end{array}$ & $\begin{array}{l}\text { Diâmetro de ramos } \\
\text { mm }\end{array}$ & $\begin{array}{c}\text { Gemas brotadas } \\
\%\end{array}$ & $\begin{array}{c}\text { Brotos por gema } \\
\text { Brotos }^{-1}\end{array}$ \\
\hline \multicolumn{5}{|l|}{ Poda (P) } \\
\hline $1^{\mathrm{a}}(26-08-13)$ & $49,93 \mathrm{~b}$ & $5,61 \mathrm{ab}$ & $100 \mathrm{a}$ & $1,41 \mathrm{a}$ \\
\hline $2^{\mathrm{a}}(09-09-13)$ & $50,46 \mathrm{~b}$ & $5,56 \mathrm{~b}$ & $100 \mathrm{a}$ & $1,34 \mathrm{a}$ \\
\hline $3^{\mathrm{a}}(23-09-13)$ & $46,78 \mathrm{~b}$ & $5,58 \mathrm{~b}$ & $100 \mathrm{a}$ & $1,34 \mathrm{a}$ \\
\hline $4^{\mathrm{a}}(07-10-13)$ & $68,15 \mathrm{a}$ & $6,15 \mathrm{a}$ & $100 \mathrm{a}$ & $1,43 \mathrm{a}$ \\
\hline Teste F & $11,643^{* *}$ & $3,610^{*}$ & $1,00^{\mathrm{ns}}$ & $0,186^{\text {ns }}$ \\
\hline \multicolumn{5}{|l|}{ Etefom (E) } \\
\hline 0 & 45,28 & 5,43 & 100 & 1,18 \\
\hline 720 & 53,44 & 5,75 & 100 & 1,34 \\
\hline 1440 & 56,38 & 5,81 & 100 & 1,62 \\
\hline 2160 & 60,25 & 5,92 & 100 & 1,37 \\
\hline Teste F & $5,004^{*}$ & $2,012^{\mathrm{ns}}$ & $1,00^{\mathrm{ns}}$ & $2,772^{*}$ \\
\hline Regressão & $\mathrm{L}^{(1)}$ & - & - & $\mathrm{Q}^{(2)}$ \\
\hline Teste F (P x E) & $0,417^{\text {ns }}$ & $0,518^{\mathrm{ns}}$ & $1,00^{\mathrm{ns}}$ & $1,396^{\mathrm{ns}}$ \\
\hline $\mathrm{CV}(\%)$ & 21,09 & 10,39 & 0,00 & 31,47 \\
\hline
\end{tabular}

Médias seguidas por letra diferente, diferem entre si a $5 \%$ pelo teste de Tukey. $*$ significativo $(\mathrm{p}<0,05)$; ** significativo $(\mathrm{p}<0,01)$; ns não significativo; L - modelo linear; $\mathrm{Q}$ - modelo quadrático ${ }^{(1)} \mathrm{v}=46,659+1,5948 * \mathrm{x} \mathrm{R}^{2}=0,94 \quad{ }^{(2)} \mathrm{v}=1,1475+0,0005 \mathrm{x}-2^{-07} \mathrm{X}^{2} \mathrm{R}^{2}=0,79$

\section{CONCLUSÕES}

O ciclo produtivo da videira 'Isabel' é menor na safra de inverno (podas em março e abril), enquanto a safra de verão (podas de agosto a outubro) apresentou ciclos mais longos.

Dentro de cada safra (inverno ou verão), o crescimento da videira é influenciado pelas épocas de poda.

Na safra de verão, poda realizada no início de outubro proporcionou maior comprimento de ramos, enquanto na safra de inverno isso ocorre nas podas realizadas em abril.

A brotação de gemas é elevada nas podas realizadas na safra de verão.

As doses de Etefom influenciam o comprimento do ramo de forma linear positiva e, para o número de brotos por gema, o efeito foi quadrático aumentando a brotação até a dose de $1440 \mathrm{mg} \mathrm{L}^{-1}$, ambos apenas na safra de verão.

\section{REFERÊNCIAS}

Albuquerque TCS, Dechen AR \& Castro PRC (2000) Retardadores de crescimento e características nutricionais das cultivares de videira Thompson seedless e Italia. Scientia Agricola, 57:4553.

Anzanello R, Souza PVD \& Coelho PF (2012) Fenologia, exigência térmica e produtividade de videiras 'Niágara Branca', 'Niágara Rosada' e 'Concord' submetidas a duas safras por ciclo vegetativo. Revista Brasileira de Fruticultura, 34:366-376.

Brunetto G, Kaminski J, Melo GWB, Gatiboni LC \& Urquiaga S (2005) Absorção e redistribuição do nitrogênio aplicado via foliar em videiras jovens. Revista Brasileira de Fruticultura, $27: 110-114$

Camargo UA (2004) Técnicas de produção vitícola com ciclos sucessivos em condições tropicais. In: $1^{\circ}$ Workshop Internacional de Pesquisa, Recife / Petrolina. Anais, Embrapa Uva e Vinho. p. 85-95.

Camargo UA, Tonietto J \& Hoffmann A (2011) Progressos na Viticultura Brasileira. Revista Brasileira de Fruticultura, 33:144149. 
Conradie WJ (1991) Distribution and translocation of nitrogen absorbed during early summer by two-year-old grapevines grown in sand culture. American Journal of Enology and Viticulture, 42:180-190.

Embrapa (2013) Sistema brasileiro de classificação de solos. $3^{\mathrm{a}}$ ed. Brasília, Embrapa. 353p.

Faria SS, Wander AE, Rocha LCT \& Chaves RQ (2013) Produção de uvas como atividade inovadora da agricultura familiar no Estado de Goiás. Goiânia, Segplan / Instituto Mauro Borges. 12p. (Conjuntura econômica goiana, 2).

Fracaro AA \& Pereira FM (2004) Efeito do Ethephon sobre a brotação e vigor dos ramos da videira "Niágara Rosada" (Vitis labrusca L.). Revista Brasileira de Fruticultura, 26:399-402.

Fracaro AA, Pereira FM \& Nachtigal JC (2004a) Uso do Ethephon antes da poda de produção em videira 'Niágara rosada' (Vitis labrusca L.). Revista Brasileira de Fruticultura, 26:97-100.

Fracaro AA, Pereira FM, Nachtigal JC \& Barbosa JC (2004b) Efeito do Ethephon sobre a produção da uva 'Niágara Rosada' (Vitis labrusca L.), produzida na entressafra na região de JalesSP. Revista Brasileira de Fruticultura, 26:82-85.

Gomes APO, Borges RME, Gonçalves NPS, Alves EOS \& Leão PCS (2007) Fenologia e potencial produtivo de uvas para suco da coleção de germoplasma da Embrapa Semiárido. In: $2^{\text {a }}$ Jornada de Iniciação Científica da Embrapa Semiárido, Petrolina. Anais, Embrapa Semiárido. (Documentos, 205).

Jacskon DI \& Cherry NJ (1988) Prediction of a district's graperipening capacity using a latitude-temperatura index (LTI). American Journal of Enology and Viticulture, 39:19-28.

Leão PCS \& Silva EEG (2003) Brotação e fertilidades de gemas em uvas sem sementes no Vale do São Francisco. Revista Brasileira de Fruticultura, 25:375-378.

Maia JDG, Camargo UA \& Nachtigal JC (2002) Avaliação da cv. Isabel em três sistemas de condução e em dois porta-enxertos para a produção de suco em região tropical. In: $17^{\circ}$ Congresso Brasileiro de Fruticultura, Belém. Anais, SBF. p.280-280

Monaco Neto LC \& Scarpare Filho JA (2012) Desenvolvimento de videira 'Niágara rosada' podada em diferentes épocas. Revista de Agricultura, 87:165-171

Neis S, Santos SC, Assis KC \& Mariano ZF (2010) Caracterização fenológica e requerimento térmico para a videira 'Niágara Rosada' em diferentes épocas de poda no Sudoeste Goiano. Revista Brasileira de Fruticultura, 32:931-937.

Pedro Júnior MJ \& Sentelhas PC (2003) Clima e produção. In: Pommer CV (Ed.) Uva: tecnologia de produção, pós-colheita, mercado. Porto Alegre, Cinco Continentes. p.63-107.

Pinã S \& Bautista D (2006) Evaluation of vegetative growth on several table cultivars under semiarid tropic conditions in Venezuela. Revista de la Facultad de Agronomía, 23:402-413.

Regina MA, Pereira GE, Lima LCO \& Rodrigues DJ (2003) Caracterização agronômica de cinco variedades de videira destinadas à elaboração de sucos de uvas na região de Caldas-MG. In: $10^{\circ}$ Congresso Brasileiro de Viticultura e Enologia, Bento Gonçalves. Anais, Embrapa Uva e Vinho. p.197-200.
Ribeiro DP, Corsato CE, Lemos JP \& Scarpare Filho JA (2009) Desenvolvimento e exigência térmica da videira 'Niágara rosada', cultivada no Norte de Minas Gerais. Revista Brasileira de Fruticultura, 31:890-895.

Roberto SR, Sato AJ, Brenner EA, Santos CE \& Genta W (2004) Fenologia e soma térmica (graus-dia) para a videira 'Isabel' (Vitis labrusca L.) cultivada no Noroeste do Paraná. Semina, 25:273-280

Santos CE, Roberto SR, Sato AJ \& Jubileu BS (2007) Caracterização da fenologia e da demanda térmica das videiras 'Cabernet Sauvignon' e 'Tannat' para a região norte do Paraná. Acta Scientiarum Agronomy, 29:361-366.

Sato AJ, Silva BJ, Santos CE, Bertolucci R, Santos R, Carielo M, Guiraud MC, Fonseca ICB \& Roberto SR (2008) Fenologia e demanda térmica das videiras 'Isabel' e 'Rubea' sobre diferentes porta-enxertos na Região Norte do Paraná. Semina, 29:283292.

Scarpare FV, Scarpare Filho JA, Rodrigues A, Reichardt K \& Angelocci LR (2012) Growing degree-days for the "Niagara Rosada" grapevine pruned in different seasons. International Journal of Biometeorology, 56:823-830.

Semensato LR, Campos LFC, Vendruscolo EP, Gomes DAE, Soares PKO \& Seleguini A (2015) Panorama da viticultura no estado de Goiás. In: XV Congresso Latino-americano e XIII Congresso Brasileiro de Viticultura e Enologia, Bento Gonçalves. Anais, Associação Brasileira de Enologia (ABE) / Embrapa Uva e Vinho. p.183-183.

Scarpare Filho JA \& Watanabe AT (2004) Relação entre os teores de carboidratos solúveis em raízes e os estádios fenológicos, em dois ciclos de produção. In: $6^{\circ}$ Simpósio de Viticultura do Alentejo, Évora. Anais, ATEVA / CCDRA / CVRA / DRAAI / EU. p.199209.

Schenato PG, Melo GW, Santos HP, Fialho FB, Furlanetto V, Brunetto G \& Dorneles LT (2007) Influência do Etefon na distribuição de nutrientes e carboidratos e sobre o crescimento em videiras jovens. Revista Brasileira de Fruticultura, 29:217221 .

Silva RP, Dantas GG, Naves RV \& Cunha MG (2006) Comportamento Fenológico de videira, cultivar Patrícia em diferentes épocas de poda de frutificação em Goiás. Bragantia, 65:399406.

Silva FCC, Viana AP, Silva MGO, Oliveira JG \& Gomes Filho A (2008) Caracterização química e determinação dos estádios fenológicos de variedades de videiras cultivadas no norte fluminense. Revista Brasileira de Fruticultura, 30:38-42.

Villa Nova NA, Pedro Junior MJ, Pereira AR \& Ometto JC (1972) Estimativa de graus-dia acumulados acima de qualquer temperatura base, em função das temperaturas máxima e mínima. São Paulo, Universidade de São Paulo. 8p. (Caderno de Ciências da Terra, 30)

Zapata C, Deléens E, Chaillou S \& Magné C (2004) Partitioning and mobilization of starch and $\mathrm{N}$ reserves in grapevine (Vitis vinifera L.). Journal of Plant Physiology, 161:1031-1040. 